\title{
LOS MILAGROS AMERICANOS DE IGNACIO DE LOYOLA Y LA RED DE INFORMACIÓN TRANSATLÁNTICA DE LOS JESUITAS*
}

\author{
POR \\ JONATHAN E. GREENWOOD ${ }^{1}$ \\ Investigador independiente
}

\section{RESUMEN}

Este artículo examina la red de información jesuita durante el generalato de Claudio Acquaviva (r. 1581-1615) en la Monarquía Hispánica. En particular, este estudio analiza la recolección y circulación de las series de milagros de Ignacio de Loyola (c. 14911556), el fundador de la Compañía de Jesús. Sus milagros americanos, conocidos a través de cartas y luego adaptados para su inserción en las relaciones y biografías impresas del fundador, fueron fundamentales para el desarrollo de la reputación de santidad de Loyola. A través de una serie de casos sucedidos en Madrid, Pamplona, Bogotá y Lima, este artículo explora la difusión intercontinental de noticias y el reportaje de sucesos sobrenaturales.

PALABRAS CLAVE: Ignacio de Loyola; milagros; santidad; redes de información; mundo hispano y atlántico.

\section{THE AMERICAN MIRACLES OF IGNATIUS LOYOLA AND THE TRANSATLANTIC JESUIT INFORMATION NETWORK}

\begin{abstract}
This article examines the Jesuit information network in the Spanish Monarchy during the generalship of Claudio Acquaviva (r. 1581-1615). In particular, the piece investigates the gathering and then circulation of accounts of the miracles of the Society's founder, Ignatius Loyola (c. 1491-1556). Miracles from the Americas were significant to the development of Ignatius's saintly reputation, which was made possible by letters that were then appropriated into newssheets and biographies of the founder. Through a series of case studies from Madrid, Pamplona, Bogotá, and Lima, the article explores the intercontinental dissemination of news and the reportage of supernatural events.
\end{abstract}

KEY WORDS: Ignatius Loyola; miracles; sanctity; information networks; Spanish Atlantic world.

CómO CITAR ESTE ARTículo / CITATION: Greenwood, Jonathan E. 2020. «Los milagros americanos de Ignacio de Loyola y la red de información transatlántica de los jesuitas». Hispania Sacra LXXII, 146: 491-499. https://doi.org/10.3989/hs.2020.036

Recibido/Received 30-11-2018

Aceptado/Accepted $\quad$ 06-09-2019
El proceso de canonización del fundador de la Compañía de Jesús, Ignacio de Loyola (c. 1491-1556), fue sinuoso y estuvo lleno de complicaciones debido en parte a la antipatía del Papa Clemente VIII (r. 1592-1605) hacia los jesuitas. ${ }^{2}$ Los procesos de canonización habían cambiado tras la fundación de la Sagrada Congregación de Ritos (SCR) en 1588, y a los

*Quiero agradecer a Francisco Gómez Martos y Cloe Cavero sus ayudas lingüísticas, y a los dos revisores anónimos sus comentarios y sugerencias.

1 jegreenwood@gmail.com /

ORCID iD: https://orcid.org/0000-0002-4558-6207

2 Gotor 2002, 57-65, 231-42; Wright 2010. Véase también, Papa candidatos se les demandaba ahora tanto el poseer unas virtudes determinadas, como el haber realizado una serie de milagros. Las noticias de las intercesiones milagrosas se convirtieron pues en esenciales para el progreso positivo de la causa de santidad. Pese al antagonismo papal, los jesuitas dejaron constancia escrita de los milagros de Loyola a lo largo de la segunda mitad del siglo XVI. Las noticias de los milagros del fundador circularon en forma de cartas basadas en información de primera mano, y fueron luego impresas y diseminadas a nivel mundial. ${ }^{3}$ Esto resultó en una recopilación de

3 Palomo 2005; Friedrich 2008 y 2009; Clossey 2008, 193-215; Nelles 2010; Nelles 2014 y 2015. 
datos susceptible de ser usada por los jesuitas para escribir vidas ejemplares, incluyendo la de su fundador.

Este artículo examina los esfuerzos realizados por la Compañía de Jesús para recolectar y diseminar la información existente sobre los milagros americanos de Loyola en la Monarquía Hispánica. Aunque diseñada como una herramienta administrativa, la red de información jesuita se transformó en un medio para difundir la reputación de santidad del fundador en los diferentes territorios gobernados por la monarquía, desde España a sus virreinatos. Ciertamente, la lista oficial de los milagros de Loyola aprobados por la Santa Sede no llegaría a incluir aquellos sucedidos en el Nuevo Mundo, por lo que éstos no tuvieron un efecto perceptible en su canonización. Sin embargo, la preparación y envío de información sobre los milagros americanos de Loyola resulta significativo históricamente como antecedente de las estrategias que serían utilizadas en las canonizaciones posteriores de santos americanos, tal como la de Rosa de Lima (1586-1617) en $1671 .{ }^{4}$ A través del caso de los milagros americanos de Loyola, este estudio proporciona una mirada a la circulación de noticias dentro del mundo español atlántico durante los siglos XVI y XVII. La mayor parte de las investigaciones para el proceso de canonización de Loyola tuvo lugar durante el generalato de Claudio Acquaviva ( $r$. 1581-1615). En ellas se puede discernir una red transatlántica de cartas jesuitas que incluía las ciudades de Madrid, Pamplona, Barcelona, Bogotá y Lima. Aunque las noticias estaban últimamente destinadas a Roma, fueron transmitidas a través de numerosos intermediarios, los cuales serán examinados en este artículo.

Las claves para impulsar esta red de información fueron las historias de Pedro de Ribadeneyra (1526-1611)..$^{5}$ Este jesuita toledano escribió la primera biografía de Loyola en 1572, aunque sus investigaciones continuarían después de esa fecha. En las últimas décadas del siglo XVI, Ribadeneyra solicitó información sobre los milagros de Loyola a sus correligionarios jesuitas, noticias que después usaría para escribir una breve biografía del fundador en la que se incluyeron más ejemplos de curaciones milagrosas. Esta nueva biografía fue insertada por Ribadeneyra en su Flos sanctorum, un género basado en la recopilación de vidas de santos y que gozó de gran popularidad en el mundo hispánico. ${ }^{6} \mathrm{El}$ Flos sanctorum de Ribadeneyra se imprimió en dos volúmenes entre 1599 y 1601 . En esta obra, Ribadeneyra incorporó, por primera vez, ejemplos de las intervenciones milagrosas de Loyola en el Nuevo Mundo.

Además, tras la beatificación del fundador de la Compañía en 1609 , se publicaron numerosos textos que tenían el trabajo de Ribadeneyra como referencia, entre ellos una biografía de Loyola publicada en Pamplona y que pretendía haber sido escrita por Ribadeneyra. Este aumento de escritos dio lugar a una combinación de viejos y nuevos contenidos sobre Loyola, siempre con un énfasis en los milagros realizados en las Indias. Al examinar los trabajos asociados a Ribadeneyra, puede verse cómo la biografía del santo, que se actualizaba con regularidad, sirvió para difundir información útil para fortalecer la reputación de santidad del fundador.

\footnotetext{
4 Mujica Pintilla 2013.

5 Bilinkoff 1999; Guillausseau 2007; O’Malley 2013, 257-297; Roldán Figueroa 2016; Bouvier 2017; Greenwood 2019.

6 Greenwood 2018a y 2018 b.
}

El presente artículo comienza por analizar las dudas iniciales que tuvo Ribadeneyra sobre los milagros realizados por Loyola, dudas que, no obstante, darían lugar a un coleccionismo frenético de milagros durante la última década del siglo XVI, y que finalmente culminarían con la inclusión de la vida de Loyola en su Flos sanctorum. A pesar de que esta obra se reimprimió varias veces, la narración de la vida de Loyola no fue alterada en las distintas ediciones. En todas ellas, la vida incluía la narración de una serie de milagros caribeños que hasta entonces habían circulado solo en forma de cartas. Después de la beatificación de Loyola en 1609, aparecieron numerosas nuevas publicaciones. En 1610 se imprimió en Pamplona una nueva biografía atribuida a Ribadeneyra, pero realizada sin su consentimiento, que comprendía, en un mismo tomo, el Flos sanctorum y unas relaciones impresas en Barcelona en las que se sintetizaban los milagros de Loyola en Perú. A partir del caso analizado en este artículo se pueden proyectar conclusiones más amplias sobre cómo eran percibidos los milagros y sobre cómo circulaba la información sobre los mismos a través de la imprenta durante la edad moderna. A su vez, este análisis intercontinental comprende también elementos locales. ${ }^{7}$

\section{EL COLECCIONISTA DE MILAGROS}

Los esfuerzos por reunir los milagros llevados a cabo por Loyola comenzaron con Ribadeneyra. Nacido en Toledo en 1526, el ingreso de Ribadeneyra a la Compañía tuvo lugar diez días antes de que el Papa Pablo III otorgara su aprobación oficial a la nueva orden. ${ }^{8}$ Aunque ya pronto, en 1547, Ribadeneyra quisiese escribir una biografía de Loyola, poco es lo que avanzó en esta materia hasta que el General Francisco de Borja (r. 1565-1573) le encargó la tarea de comenzar a escribir en 1567. La Vita Ignatii Loiolae no vio la luz de la imprenta hasta 1572, y del mismo solo se imprimieron quinientas copias, la mitad de una tirada típica. ${ }^{9}$

Los primeros cuatro libros de la Vita Ignatii relatan la vida devota de Loyola en el contexto de la expansión global de los jesuitas bajo el liderazgo de inspiración divina de su fundador. No obstante, Ribadeneyra fue precavido y evitó usar la palabra "milagro» a la hora de describir cualquier faceta de la vida de Loyola. El libro quinto enumeraba las virtudes de Loyola, entre ellas la caridad, la humildad, la obediencia y la vigilancia. El libro concluía con una valoración de los milagros de Loyola, aunque Ribadeneyra, para evitar críticas, se cuidó de señalar que dichos milagros no estaban necesariamente asociados con la santidad de Loyola. Al contrario, Ribadeneyra los atribuyó a los jesuitas, quienes, en todas sus misiones globales, trabajaban para convertir a «infideles» al catolicismo. ${ }^{10}$ Dichas conversiones, explicaba Ribadeneyra, eran mayores auténticos milagros que curaciones, exorcismos y otros remedios similares. Aunque procuró incluir ejemplos en los que Loyola había curado, exorcizado

\footnotetext{
7 Ditchfield 1995 y 1998.

8 Pedro de Ribadeneyra, «De actis Patris Nostri Ignatii» en: Fernández Zapico y Dalmases 1943-1965, 2: 349-350.

9 «Una carta de Antonio Remiro a Antonio Araoz, Nápoles, 5 de mayo de 1572», en: Fernández Zapico y Dalmases 1943-1965, 4: 934. Vea también O'Malley 2013, 273. Sobre la cantidad de copias que era común en una tirade impresa, sigo a Bouza Álvarez 2000, 87.

10 Ribadeneyra 1572, ff. 208-217.
} 
y salvado personalmente a náufragos, Ribadeneyra minimizó el valor milagroso de esas acciones y evitó considerar las curaciones realizadas por Loyola como milagros. Desde su punto de vista, el milagro más significante que debía atribuirse a Loyola era la propia fundación de la Compañía de Jesús.

Poco después del nombramiento del nuevo General Everardo Mercuriano en 1573, Ribadeneyra acabó desterrado de Roma, lo que le llevó a regresar a su ciudad natal de Toledo y más tarde, desde 1583, a Madrid, en donde permanecería hasta su muerte en $1611 .{ }^{11}$ Una vez en Madrid, Ribadeneyra publicó una traducción de la Vita Ignatii al castellano. Esta nueva versión, en la que apenas había introducido cambios, no identificaba a Loyola como un taumaturgo, es decir, como aquel que realizaba milagros y que generalmente estaba asociado con los santos católicos.

\section{NECESIDAD DE MILAGROS}

En 1593, jesuitas de diversas partes del mundo se reunieron en Roma con motivo de la 5ạ Congregación General. Uno de los propósitos de esta asamblea era el lanzamiento de una campaña para proporcionar las pruebas necesarias para comenzar el proceso de canonización de Loyola a la nueva SCR. ${ }^{12}$ Este procedimiento era complejo dado que la SCR exigía evidencia concreta de los milagros y virtudes de un candidato. De acuerdo con la definición propuesta en 1601 por el agustino romano Angelo Rocca, «canonizatio est canonica et publica sanctatis alicuius hominis approbatio, qua quis Catalogo sanctorum adscriptis declaratur et solemniter promulgatur ${ }^{13}{ }^{13}$ En la práctica, el proceso de canonización comenzaba con un análisis exhaustivo de la vida, las virtudes y los milagros del candidato. Seguidamente la SCR evaluaba los méritos del candidato mediante interrogatorios a testigos pertinentes. ${ }^{14}$ En caso de que la SCR aprobara la canonización, era entonces el Papa quien decidía si la veneración sería universal o local. Con este fin, la Compañía inició una serie de investigaciones locales sobre la santidad de Loyola en 1594.

Dos años después, Ribadeneyra se dirigió al Provincial de la Congregación de jesuitas españoles con un mensaje sobre la canonización. Había algunos problemas con respecto a la reputación de santidad de Loyola. En primer lugar, Loyola no contaba con los milagros necesarios para canonizar a un santo, ya fuesen aquellos realizados en vida o aquellos sucedidos post mortem, pues su milagro más extraordinario se reducía a la fundación de la Compañía, y a la consecuente evangelización del mundo emprendida por la misma. ${ }^{15}$ Por tanto, el argumento más importante de la Vita Ignatii interfería negativamente con el proceso de canonización. Se hacía necesario atribuir a Loyola milagros de estilo más

11 Everardo Mercuriano, «Instrucción para los Padres provinciales de Castilla y Toledo, Roma, 10 de julio de 1574» en: Ribadeneyra 19201923, 2: 494-495.

12 Padberg, O'Keefe y McCarthy 1994, 212.

13 Rocca 1601, 5.

14 Ditchfield 1995, 215, 217; Rocca 1601, 17-23, 72-73, 77-78, 99-100.

15 «Carta Pedro de Ribadeneyra al Provincial de la Congregación de España, Madrid, 5 de abril de 1597», en: Scripto de Sancto Ignatio de Loyola (en adelante, MI Scripta), 1904-1918, 2: 402-03. tradicional, como realizar curaciones tras su fallecimiento, hechos que ayudaban a acelerar los casos de canonización. Sin estas intervenciones, su reputación de santo era problemática, al menos según la percepción del SCR. El conseguir pruebas de la eficacia sobrenatural de Loyola se convirtió pues, en una necesidad. Ribadeneyra y los jesuitas se vieron apremiados a hacer un importante esfuerzo por encontrar curaciones y exorcismos realizados por el fundador de la Compañía.

Esta circunstancia explica que la resistencia inicial de Ribadeneyra a promulgar los milagros de Loyola sufriera un revés en 1601, cuando se publicó en Madrid el segundo volumen de su Flos sanctorum. Este volumen incluía una vida de Loyola que, aunque truncada, estaba esta vez llena de milagros. El origen de este nuevo proyecto probablemente haya que buscarlo en la carta de Ribadeneyra al Provincial español de la Congregación datada en 1597, así como en la carta que, un año más tarde, Acquaviva enviaría a todos los provinciales animando a los jesuitas a escribir historias de conversiones, santidad y las calamidades que asolaban a enemigos y desertores de la Compañía de Jesús. ${ }^{16}$ En la correspondencia entre Ribadeneyra y Acquaviva, el primero se mostraba inseguro con respecto a la historia - de la cual no se especifica su nombre- que estaba escribiendo, una obra que el segundo le recordaba que era importante y útil para la edificación de otros. Aunque Ribadeneyra había terminado una historia de la asistencia española antes de su muerte en 1611, es más que probable que la historia que discute en su correspondencia con Acquaviva sea su Flos sanctorum, en donde se enumeraban milagros de santos entre los cuales se hallaba Loyola. ${ }^{17}$ Ribadeneyra tenía que seleccionar solamente los milagros de mayor relevancia para mostrar la santidad de Loyola, aquellos que mejor expresasen la milagrosa ejemplaridad del fundador.

Ribadeneyra era muy consciente de las limitaciones de sus biografías de Loyola, pues en el prefacio a la nueva biografía alegaba no haberle dedicado suficiente tiempo a «los otros muchos milagros que Dios ha obrado por intercession deste B[eato] Padre», una laguna que debía colmarse lo antes posible. ${ }^{18}$ Aunque el proceso se había centrado en Europa, el Flos sanctorum también incluía noticias sobre las intervenciones llevadas a cabo por Loyola en el Nuevo Mundo. De los más de setenta milagros que comprendía su narración, solo dos habían tenido lugar en las Américas y ellos incluían el apaciguamiento de varios fenómenos huracanados en el Caribe. Con todo, Ribadeneyra mantuvo que la fundación de la Compañía de Jesús por Loyola era un milagro «ta[n] gra[n]de, y tan notorio, que aunque faltassen todos los otros, solo deuria bastar para conocer y estimar la santidad que el Señor dio a este venerable Padre». ${ }^{19}$ A pesar de la necesidad de incrementar la lista de milagros en respuesta a los problemas en torno a la canonización de Loyola, Ribadeneyra no abandonó su creencia de que

16 Archivo Romano de la Compañía de Jesús, Roma (en adelante, ARCJ), Inst. 121, 174v: "Carta de Claudio Acquaviva a todos los provinciales jesuitas, Roma, 26 de septiembre de 1598».

17 ARCJ, Hisp. 94: Pedro de Ribadeneyra, Historia de la Compañía de Jesús de las Provincias de España y parte de las del Piru y Nueua España y Philippinas, c. 1611.

18 Ribadeneyra 1599-1601, 2: 846-847.

19 Ribadeneyra 1599-1601, 2: 869. 
la creación de la Compañía era el milagro más importante realizado por Loyola.

\section{LOYOLA Y LOS HURACANES EN EL CARIBE}

La documentación sobre los milagros meteorológicos va más allá de lo dicho por Ribadeneyra. Loyola intervino para frenar un huracán que, según Ribadeneyra, tuvo lugar el 23 de septiembre de 1598 cerca de la costa de Jamaica, y que afectó a un buque que viajaba desde Trinidad, en Cuba, hacia Cartagena de Indias en la actual Colombia. ${ }^{20}$ Aunque Ribadeneyra empleó la palabra «tormenta» en su narración, los españoles de la edad moderna usaban indistintamente esa misma palabra, "tempestad» y "huracán» cuando se referían a los huracanes del Caribe..$^{21}$ Los relatos de la edad moderna tienden a ser menos precisos a la hora de describir los parámetros propios de estos fenómenos climatológicos.

Las noticias del milagro de Loyola circularon a través de la red de información jesuita, empezando en Bogotá, desde donde llegarían hasta Ribadeneyra en Madrid. El Provincial mexicano Francisco Váez, en su carta anual para la Provincia de México, hizo referencia al milagro de 1598. Durante cuarenta y ocho horas, fuertes vientos y mares tormentosos habían asolado el barco en el que iban los padres Alonso Medrano y Francisco de Figueroa. Los dos jesuitas imploraron una serie de invocaciones, entre ellas a la Virgen María y a diversos santos, pidiéndoles su intervención para salvar la embarcación. Uno de los dos jesuitas, no especificado por Váez, pensó que Loyola habría de ser un santo dado que su firma había curado milagrosamente a gente en Roma y en toda Italia. Solo una reliquia de Loyola podría salvarlos. Casualmente, uno de los dos jesuitas tenía «un pedazo de cilicio con que el santo [Loyola] había afligido su carne».22 El cilicio era una tela gruesa hecha con lana de cabra que se usaba como una camisa de pelo para la mortificación corporal. ${ }^{23}$ Con el objeto en la mano, todos a bordo, incluido el arzobispo Bartolomé Lobo Guerrero, gritaron "santo padre Ignacio, ayudadnos». ${ }^{24} \mathrm{El}$ viento entonces cesó y el mar se calmó. El arzobispo se mostró tan agradecido por tal intervención que prometió celebrar una misa y hacerse responsable del banquete que acompañaría a la canonización, aunque ésta estaba todavía por llegar. ${ }^{25}$

El general jesuita Claudio Acquaviva (r. 1581-1615), no obstante, tuvo constancia del milagro por medio de Figueroa y Medrano mucho antes de que la misiva de Váez llegara a sus manos. El 28 de octubre de 1598, Figueroa escribió una carta, hoy perdida, desde Cartagena a la cual Acquaviva respondió en agosto de 1599 con una orden de examinar a los testigos del milagro. ${ }^{26}$ Un mes más tarde, Acquaviva escribió a Medrano para transmitirle su alegría de saber

\footnotetext{
20 Ribadeneyra 1599-1601, 2: 867-868.

21 Alvar Ezquerra 1997, 206.

22 Francisco Váez, "Carta anua de la Provincia de México, México, 23 de septiembre de 1599», en: Zubillaga y Rodríguez 1956-1991, 6: 605.

23 Covarrubias y Orozco 1611, 282v.

24 Váez, "Carta anua...de 1599», en Zubillaga y Rodríguez 19561991, 6: 606

25 Váez, "Carta anua de 1599», en Zubillaga y Rodríguez 19561991, 6: 606.

26 «Carta de Claudio Acquaviva a Francisco de Figueroa, Roma, 23 de agosto de 1599», en Engaña y Fernández 1954-1986, 6: 775.
}

que Loyola había realizado dicho milagro, aunque el general no reveló su fuente. ${ }^{27}$ Medrano, al año siguiente, pidió a Lobo Guerrero que comenzara el procedimiento para verificar el milagro que había ocurrido en el Caribe. El arzobispo aceptó y el proceso dio comienzo el 18 de abril de 1600 . Supuestamente, poco después de que terminaran los trámites, Medrano y Figueroa viajaron a España y durante el viaje hicieron frente a otros dos desastres náuticos cerca de las Bahamas y de las Azores. En medio del caos, tanto la documentación original procedente de Bogotá como un puñado de cartas se perdieron en el mar. Se cree que el único documento que ha sobrevivido es una copia refrendada emitida en Bogotá, conservada actualmente en Roma. ${ }^{28}$

\section{LOS TRÁMITES EN BOGOTÁ}

Medrano comenzó el proceso con su relato del milagro, que presentaba numerosas contradicciones. Para empezar, declaró que la "rezia tormenta» había ocurrido en septiembre de 1599 y que los pasajeros habían depositado su confianza en las reliquias de Loyola, algo que era incoherente con otras versiones del mismo hecho. ${ }^{29}$ Medrano propuso que se conmemorara la festividad de Loyola desde ese día, bajo el argumento de que el fundador había sido beatificado, lo que no era el caso. Entre finales de 1599 y principios de 1600, a México habían llegado desde España informes que erróneamente declaraban la beatificación de Loyola. ${ }^{30}$ Poco después, esta información incierta se extendió desde México hasta Bogotá. El Papa Clemente VIII (r. 1592-1605), declaró Medrano, había requerido «información» sobre la autenticidad del milagro en cuestión. Medrano, no obstante, ignoraba la hostilidad de Clemente con respecto al proceso de canonización de Loyola. ${ }^{31}$

Los testigos que declararon en Bogotá fueron consistentes en su descripción de los hechos acaecidos frente a las costas de Jamaica. Los clérigos Diego Vázquez y Martín Gaytán, por ejemplo, hablaron de una "rezia tormenta» y, al igual que Medrano, afirmaron que el milagro tuvo lugar el 24 de septiembre y que se utilizaron numerosas reliquias. ${ }^{32}$ El testimonio del cura Miguel Budi constituye una excepción dado que habló de «vna Muy Grande tormenta y tempestad de vn huracán deschecho, El qual duró tres días y sus noches». ${ }^{33}$ Budi creía que las condiciones climatológicas eran la fase final de un huracán que arrastraba intensas lluvias y fuertes vientos. Ninguno de los otros testigos en ningún momento describió la tormenta específicamente como un huracán. Budi, sin haber sido persuadido por

\footnotetext{
27 «Carta de Claudio Acquaviva a Alonso Medrano, Roma, 20 de septiembre de 1599», en Engaña y Fernández 1954-1986, 6: 799.

28 Medina 2004, 614. Aunque Medina transcribió el documento, he usado el original, que puede hallarse en Archivo del Postulador General de la Compañía de Jesús, Roma (en adelante APGCJ), número 10, ff. 431-440: Informaçión hecha en Sante Fe del Nuevo Reyno de Granada..., 1600.

29 Informaçión, 431r.

30 Informaçión, 431r; "Carta de Francisco Váez a Claudio Acquaviva, México, entre 5 de diciembre de 1600 y 17 de febrero de 1601», en Zubillaga y Rodríguez 1956-1991, 7: 391.

31 Informaçión, 431r. Véase también Gotor 2002, 57-65, 231-242; Wright 2010.

32 Informaçión, fol. 432.

33 Informaçión, 433v.
} 
Medrano, Figueroa o Lobo Guerrero, también concluyó que el incidente en el Caribe había sido un milagro. ${ }^{34}$ Fueron las oraciones en conjunción con el cilicio, según Budi, las que motivaron el cambio meteorológico. A través de los testimonios, las expresiones «maravilla» y «milagro» se utilizaron con tanta frecuencia que acabaron por combinarse, a pesar de que desde el punto de vista teológico dicha relación era inconsistente. Las maravillas eran descritas como fenómenos preternaturales, mientras que los milagros eran sobrenaturales e instantáneos. ${ }^{35}$ En este caso, el clima, como fenómeno de la naturaleza, se topó con fuerzas sobrenaturales que frenaron ipso facto los remanentes de un huracán, aunque se desconoce cómo Budi pudo saber en qué fase se encontraba el huracán.

Medrano no puso en duda el testimonio de los testigos puesto que Lobo Guerrero había enviado a dos jesuitas a Madrid y a Roma. El arzobispo pretendía que los dos correligionarios obtuvieran permiso para que la Compañía pudiera establecer instituciones en la archidiócesis de Santa Fe. Las cartas enviadas a el Provincial de Perú no hallaron respuesta. La única opción viable parecía ser la de realizar en persona las peticiones a Acquaviva y al monarca español. ${ }^{36}$ No obstante, Medrano y Figueroa continuaban interrogando a los testigos a principios de mayo, de manera que salieron a finales de ese mismo mes desde Bogotá hacia Cartagena, que era el último punto en la ruta marítima de Tierra Firme. Los barcos que seguían esta ruta desde España normalmente llegaban a Cartagena entre septiembre y octubre, permanecían allí anclados durante la estación invernal y regresaban a Europa en primavera. ${ }^{37}$ En cualquier caso, poco más es lo que se conoce de este viaje excepto que Medrano llevaba consigo un informe para Acquaviva sobre la misión en el Nuevo Reino. En este documento, Medrano hablaba brevemente de la «maravilla» que había tenido lugar frente a las costas de Jamaica, cuando Loyola «milagrosamente» puso fin a la tormenta. El informe también hacía mención de la información que había conseguido reunirse sobre el milagro para que se enviara al General jesuita y a la Santa Sede con el fin de acelerar el proceso de canonización. ${ }^{38}$ Se sabe que este documento llegó a Roma, pero se desconoce cuándo.

\section{LAS NOTICIAS LLEGAN A MADRID}

El milagro meteorológico apareció en una biografía de Loyola publicada en Madrid a mediados de 1601 . Se trataba del Flos sanctorum de Ribadeneyra, quien culminaba así con el acopio de noticias sobre el milagro atribuido a Loyola. De dónde obtenía la información Ribadeneyra sobre los hechos acaecidos en el Caribe, es una incógnita. Es posible que tuviese copias de las misivas que se habían enviado inicialmente desde el Nuevo Reino, o quizá de la carta anual de Váez. Desde el tiempo de secretario Juan Alfonso de Polanco (1517-1576), los jesuitas conservaban copias de la correspondencia enviada a Roma, lo que facilitaba la circulación de noticias desde que salían de las misiones alrededor

\footnotetext{
34 Informaçión, 434v.

35 Covarrubias y Orozco 1611, 549v. Vea también Daston 1991.

36 Pacheco 1959-1989, 1: 79.

37 Pérez Mallaína 1998, 10.

38 ARCJ, NReQ 14, fol. 9: Alonso de Medrano, Descripción del Nuevo Reino, 1599-1600.
}

del orbe de la Compañía. ${ }^{39}$ Mucho menos probable parece un encuentro entre Ribadeneyra y los dos jesuitas que viajaban desde Bogotá, el cual habría tenido lugar en Madrid entre finales de 1600 y mayo de 1601, fecha propuesta a partir de los preliminares del libro.

Además del milagro que puso término al huracán cercano a Jamaica en 1598, Ribadeneyra incluyó otros dos milagros en los que esteban involucrados Loyola, Medrano y Figueroa. Según Ribadeneyra, los dos jesuitas habían sufrido tormentas en el Viejo Canal de Bahama y la isla Terceira del archipiélago de las Azores durante su viaje desde Bogotá hacia Europa en 1600. Estas tormentas causaron la pérdida de algunas cartas y también de la copia original de las declaraciones del testigo que había sido interrogado en Bogotá ese mismo año. Ribadeneyra identificó el barco en el que viajaban los dos jesuitas con el de Nuestra Señora de Aránzazu. ${ }^{40}$ De hecho, un barco con ese nombre que viajaba desde Tierra Firme llegó a Sevilla en algún momento de 1600 , probablemente a finales de ese año, puesto que había salido de España en enero o principios de febrero de $1600 .{ }^{41}$ A partir de estos datos, es congruente pensar que Medrano y Figueroa pudieron haber viajado en Nuestra Señora de Aránzazu en su regreso a España. La ruta de Tierra Firme que utilizaron Medrano y Figueroa iba desde Cartagena de Indias a La Habana, lo que llevaba dos o tres semanas de duración. Desde allí, los barcos navegaban a través del Viejo Canal de Bahama, que se sitúa entre Cuba y Bahamas, en dirección a las Azores. Este último viaje duraba alrededor de un mes, a lo que había que añadir otro mes más hasta llegar a Sevilla. ${ }^{42}$ Desde el momento en que los dos jesuitas llegaron a Europa hasta la publicación del Flos sanctorum, hubo solo un corto período de tiempo, lo que significa que Ribadeneyra obtuvo esta información justo a tiempo para incluirla en su apartado sobre Loyola.

Aunque las Azores eran conocidas por sus fuertes tormentas durante el invierno y la primavera, el Canal Viejo de Bahama experimentaba ciclones y huracanes con la misma frecuencia que Jamaica. ${ }^{43}$ A finales de septiembre de 1600 , un leve huracán que azotó el norte o noreste de La Habana bien podría haber sido la misma tormenta que padecieron los navegantes de Nuestra Señora de Aránzazu. ${ }^{44}$ A diferencia de lo que había sucedido en el milagro de 1598, en este caso Figueroa arrojó una reliquia al mar para así frenar la tormenta. Aunque Ribadeneyra no proporciona detalles sobre esta reliquia, es probable que se tratase de la misma prenda de cilicio que había sido usada en 1598. El uso de reliquias para calmar los mares no era raro en el Caribe, sino una de muchas estrategias entre las que también se incluían, como hemos visto, el rezo y la Eucaristía. ${ }^{45}$ Ribadeneyra no usó la palabra «huracán» para describir lo que había ocurrido cerca de Jamaica y en el Canal Viejo de Bahama, sino que habló de "tormentas», una forma de categorizar ciclones que permanecían porosos. Y una forma completamente aceptable de poner fin a estos

\footnotetext{
39 Nelles 2015; García de Castro Valdés 2012.

40 Ribadeneyra 1599-1601, 2: 868-869.

41 Chaunu y Chaunu 1955-1959, 4: 92, 108.

42 Pérez Mallaína 1998, 14, 103.

43 Reading 1990, 368.

44 Millás 1968, 92.

45 Schwartz 2015, 22; Weckmann (1962) 1992, 257.
} 
problemáticos desastres naturales era el recurso divino, bien mediante oraciones con una reliquia o con la inserción de esta última en el agua. Parece ser que los jesuitas en España se negaban a definir estos fenómenos climatológicos como huracanes, a pesar de que algunos de ellos habían estado en el Nuevo Mundo y podían haber consultado informes sobre los frecuentes huracanes del Caribe.

\section{COPIA Y DUPLICACIÓN EN PAMPLONA}

Después de la primera publicación del Flos sanctorum en 1601, Ribadeneyra no realizó ningún cambio en el apartado sobre Loyola, a pesar de que la obra fue nuevamente impresa en 1604 y 1609. No obstante, tras la beatificación de Loyola en 1609 también aparecieron ediciones no autorizadas de la obra. Entre ellas se halla la Vida de Ignacio de Loyola de 1610, publicada en Pamplona de la mano del impresor Carlos de Labayen y del editor Cristóbal de Areyzaga. Este último no era un padre jesuita sino un beneficio de linaje vasco. ${ }^{46}$ Cristóbal y sus hermanos mayores Bernardo y Felipe - eran parte de los ejércitos austríacos de los Habsburgo, primero en las guerras otomanas (15931606) y después en la Revuelta bohemia (1618-1620). ${ }^{47}$ En el momento en el que fue publicada la biografía pamplonesa, ni Areyzaga ni sus hermanos se hallaban reclutados en Europa central.

Este nuevo libro sobre Loyola reproducía la biografía del fundador jesuita escrita por Ribadeneyra en su Flos sanctorum. Era una obra en honor del santo vascongado proyectada para consumo local. Sus escasas dimensiones (11 x 8 centímetros también conocido como in- $24^{\circ}$ ) sugieren que el libro estaba destinado a la lectura privada y de viaje. El impresor de Amberes Cristóbal Plantino (1520-1589) explicó en una carta de 1586 que él imprimió las obras de los poetas romanos Virgilio y Horacio en ese tamaño porque eran útiles para «pauvres escholiers et ceux qui voyageants veulent porter avec soy beaucoup de livres en peu de masse.$^{48}$ Estos pequeños libros solían representar un porcentaje relativamente pequeño en la producción de un impresor. En el caso de la imprenta de Plantino, a partir del estudio de los catálogos de 1572, 1584 y 1615 se puede concluir que los libros in- $24^{\circ}$ sumaban una media del tres por ciento de las ediciones impresas. ${ }^{49}$

El impresor de la Vida publicada en Pamplona, Carlos de Labayen, solo imprimió otro libro in- $24^{\circ}$, una edición de la Imitación de Cristo en $1619 . .^{50}$ Por lo demás, su repertorio era diverso y en él se hallaban obras como La Celestina, textos bilingües en vasco y castellano de Juan de Berian, De oratore de Cicerón, y vidas de santos, entre las que se incluyen las de Fermín, el patrón de Pamplona, y los jesuitas Francisco Xavier y Luis Gonzaga. A partir de este repertorio, puede decirse que Labayen orientaba su producción libresca al beneficio económico, pues estaba interesado únicamente

46 Otazu y Díaz de Durana 2008, 470.

47 Roxas y Contreras 1768, 1: 854-855.

48 "Carta de Cristóbal Plantino a Carlos de Tisnac, Amberes, 13 de septembre de 1586», en: Correspondance de Christophe Plantin 1883 1918, 8: 36-37.

49 Voet 1969-1972, 2: 168.

50 Tomás de Kempis 1619. La única copia que se conoce se halla en la Biblioteca Pública de Évora. en lo que los consumidores querían leer. Por otra parte, él no era nativo en la región sino de Zaragoza, desde donde había trasladado su negocio impresor a Pamplona en 1607. Desde muy pronto, dada su tendencia a publicar ediciones no autorizadas, las relaciones de Labayen con otros impresores bien establecidos en Pamplona no fueron buenas. ${ }^{51}$ Solo han sobrevivido hasta hoy tres copias de la Vida de Ignacio, que se hallan respectivamente en la Bibliothèque Saint-Geneviève en París, la Biblioteca Nacional de Portugal en Lisboa y la John Carter Brown Library en Providence, Rhode Island, Estados Unidos, siendo esta última la que aquí hemos consultado.

En sus biografías de Loyola, Ribadeneyra habló en ocasiones sobre los primeros años de vida del fundador jesuita en las Naciones Vascongadas. En el Flos sanctorum hizo referencia a un exorcismo que había tenido lugar en el hospital de Azpeitia, su ciudad natal. Estando en ese hospital, en abril de 1535, Loyola entró en contacto con una mujer que había estado poseída durante cuatro años. Loyola «respondio con mucha humildad, que no era Sacerdote, ni merecia tanto delante de nuestro Señor; pero que rogaria à su diuina Magestad por ella». ${ }^{52}$ Al margen de esta referencia en el Flos sanctorum, Ribadeneyra apenas hizo mención de las Naciones Vascongadas. Además, no hay ninguna evidencia de que Ribadeneyra mantuviera correspondencia o conociera a Areyzaga, lo que hace prácticamente imposible que la biografía publicada en Pamplona fuera el resultado de un trabajo de colaboración.

En el prefacio a los lectores, Areyzaga explicó cuáles habían sido las razones que le habían llevado a escribir esta biografía ad hoc de Loyola a partir de la obra de Ribadeneyra: "ofrecemos aqui al piadoso Letor, la mas breue y recogida, que anda al fin de la tercera parte de su Flos sanctorum, sin añadir, ni quitar nada de la sustancia, y contexto original, excepto los Capitulos 14 y 17 del libro tercero». ${ }^{53}$ En efecto, el texto de Ribadeneyra había sido abreviado por Areyzaga, quien también había añadido dos capítulos nuevos del volumen de Areyzaga era un proyecto dedicado a la provincia para conmemorar a Loyola, su «santo alumno». Ese mismo año, desde Guipúzcoa se comenzó a presionar para que el jesuita fuese nombrado santo patrón de la región. ${ }^{54}$ La petición pronto recibió la aprobación, en parte gracias a que Loyola había nacido en Azpeitia, en donde además había exorcizado a una mujer en el hospital local. ${ }^{55} \mathrm{El}$ niño Loyola carecía de una historia vinculada con su localidad natal, una laguna que Areyzaga intentó colmar con esta historia.

No obstante, Areyzaga necesitaba ayuda económica para publicar el libro. Aunque residía en Pamplona, decidió pedir ayuda a la Junta General de Guipúzcoa, una institución similar a la de las Cortes que existían en el resto de España; su solicitud de 1610 quedó registrada en los documentos oficiales de la Junta. Según consta en esos registros, Areyzaga

51 Ruiz Astiz 2014, 2-4.

52 Ribadeneyra 1599-1601, 2: 848.

53 Ribadeneyra 1610, signatura +3.

54 APGCJ, número 23, documento 3, n.p.: Carta de Pedro Manso Zuñiga a un destinatario desconocido, San Sebastián, 4 de febrero de 1610.

55 Henao 1689-1691, 1: signatura. [§] [2]r; Díez de Salazar y Ayerbe Iríar 1990-2008, 18: 24, 49. 
había «alcançado liçençia para ello, se le dé alguna ayuda de costa. Y para que se heche de ber de la forma que se a conpuesto el libro de las obras del dicho beato Ynaçio de Loyola ymbía un libro scripto en molde para que Su Señoría lo bea». ${ }^{56}$ La publicación de la obra en Pamplona se hacía necesaria dado que Guipúzcoa careció de imprentas hasta 1667, por lo que la región necesitaba subcontratar la producción. ${ }^{57}$ El proyecto de Areyzaga contó además con la ayuda de los jesuitas de Pamplona, quienes contribuyeron a la financiación. Los miembros de la Compañía se apoyaban en intermediarios con buenas conexiones, como era el caso del propio Areyzaga, para canalizar las peticiones de ayuda económica para los proyectos. La Junta, sin embargo, se negó a cubrir los gastos que quedaban. ${ }^{58}$ No sería esta la última vez que la Junta rechazara peticiones hechas desde Pamplona. En 1611, un año después de que Areyzaga presentara su solicitud, el virrey de Navarra pidió ayuda económica para edificar un retablo en honor de Loyola en Pamplona, y la Junta hizo caso omiso de esta iniciativa. ${ }^{59}$

\section{LOYOLA Y UN FRAILE DOMINICO EN LIMA}

A pesar del rechazo de la Junta, el libro pasó a la imprenta con unos contenidos idénticos a los del texto sobre Loyola incluido en el Flos sanctorum de Ribadeneyra, con la excepción de los dos añadidos de Areyzaga ya mencionados: un capítulo sobre la beatificación de 1609 y otro sobre un milagro que ocurrió en Lima. Este último combinaba comentarios y fragmentos procedentes de una relación de 1609 impresa en Barcelona. Este milagro, que no se hallaba en el Flos sanctorum de Ribadeneyra, ocurrió exactamente el jueves 8 de noviembre de 1607 a las 17:00 horas, e involucraba al fraile dominico Álvaro de Molina. El fraile Álvaro era paralítico y sus correligionarios tenían que llevarlo en una silla instalada en un trineo. Él había estado leyendo la Vida de Ignacio de Ribadeneyra y luego rezando a Loyola durante ocho días, lo cual, aparentemente, le ayudó a combatir su parálisis. Primero recibió un impulso para levantarse de la silla y, acto seguido, procedió a caminar alrededor del convento. Es decir, un texto sobre la vida de Loyola le ayudó a avivar sus exánimes extremidades. ${ }^{60}$

El autor de la carta, datada el 29 de noviembre de 1607, en la que se exponía esta noticia era un cierto Rodrigo de Cabredo, un jesuita de Lima. ${ }^{61}$ Cabredo había escrito esta misiva para beneficio de otro jesuita peruano, Alonso Messía, que estaba destinado en Roma. La carta llegó a Barcelona a través de la red de información jesuita especializada en la difusión de noticias relacionadas con la Compañía y de la cual Barcelona, junto con otras ciudades portuarias como Lisboa y Sevilla, servían como centros. ${ }^{62}$ Si bien este documento ha sobrevivido al paso del tiempo, otras tres versiones del mismo procedentes de Lima y Barcelona, supuestamente impresas en 1609 con ediciones en italiano

56 Díez de Salazar y Ayerbe Iríar 1990-2008, 18: 43.

57 Fernández de Casadevante Romaní 2012, 69-75.

58 Díez de Salazar y Ayerbe Iríar 1990-2008, 18: 43.

59 Otazu y Díaz de Durana 2008, 470.

60 Ribadeneyra 1610, 175v-176r.

61 Cabredo 1609

62 Nelles 2014, 61-63. y español, se han perdido. ${ }^{63}$ Este texto llegó incluso a la imprenta alemana, como puede verse en la colección de letras jesuitas publicada en Maguncia en 1618, lo que es un índice de cómo las noticias se diseminaban de manera sistemática entre las instituciones de la Compañía. ${ }^{64}$

Un análisis comparativo de las dos fuentes demuestra que Areyzaga omitió buena parte de la descripción inicial de la relación y optó por centrase en las palabras del testigo, pues ellos eran quienes vieron y estuvieron presentes en el momento de la curación del fraile Álvaro. ${ }^{65}$ Seguidamente Areyzaga reprodujo textualmente las declaraciones de dominicos locales, Diego de Medina, el sacristán superior, y el Procurador General de los dominicos en Perú, Bartolomé de Ayala. ${ }^{66}$ Al final del capítulo, Areyzaga copió los contenidos de su fuente - Cabredo- sobre los efectos que la noticia podría tener en el enfermo. Cristóbal de Mesa, un jesuita de la misma ciudad, se encontraba cercano a la muerte a causa de una fiebre cuando los médicos que le atendían le hablaron de lo acontecido al fraile Álvaro. La noticia le llenó de tanto júbilo que pidió que le dejaran levantarse de la cama para ayudar a sus correligionarios a recitar el Te Deum en la iglesia. Poco después, la fiebre menguó. Los milagros, en cualquier caso, no terminaron ahí. Cinco más tuvieron lugar en Lima, aunque Cabredo no proporciona detalles de los mismos. ${ }^{67}$ Tanto el capítulo como la relación concluyen en ese punto; Areyzaga, no obstante, nunca mencionó la fuente de dónde sacó los datos para este capítulo sobre los milagros que se produjeron en Lima.

A pesar de que Areyzaga se resistió al nombramiento de Loyola como patrón de Guipúzcoa, el culto vascongado por el fundador jesuita precedió a la publicación en Pamplona de la Vida y no estuvo limitado a la Península Ibérica, lo que nos es conocido gracias a la costumbre jesuita de hacer circular la información. Por ejemplo, a Martín Fernández (1548-1620), el rector del colegio jesuita en la Ciudad de México, se le encargó la tarea de recopilar las diversas noticias que llegaban desde distintos puntos de la provincia. ${ }^{68}$ En la carta donde se exponían los resultados de esta investigación, Fernández señaló que Loyola curó en Oaxaca a un vasco que padecía una grave enfermedad y al que los médicos habían dado por enfermo terminal. "Oyó dezir en esta occasión las maravillas que nuestro Señor obrava por nuestro b[ienaventurado], y pidiendo una ymagen suya, y encomendándose a ella, repentinamente alcanço entera salud, que hasta oy le dura».69 Este es uno de los primeros ejemplos que mencionan la imagen milagrosa que Loyola tenía en el Nuevo Mundo.

Fernández analizó de cabo a cabo todos los elementos que determinaban la naturaleza del milagro. Los médicos habían considerado que no había otra forma de curar al hombre vasco. Por su extrema gravedad, la curación había

63 La información sobre este trabajo perdido y las ediciones italianas proceden de: Wilkinson y Ulla Lorenzo 2016: s.v. 22302-22304.

64 Litterae annuae Societatis lesu 1607 1618, 164-165.

65 Ribadeneyra 1610, 175r.

66 Ribadeneyra 1610, 175v-178v; Cabredo 1609: signatura A f. 1v, signatura A f. 2v.

67 Ribadeneyra 1610, 178v-179v; Cabredo 1609, signatura ff. [A 3].

68 Zambrano 1961-1977, 6: 608-609.

69 Martín Fernández, "Carta anua de la Provincia de México, México, 5 de mayo de 1603», en: Zubillaga y Rodríguez 1956-1991, 8: 126. Véase también Otazu y Díaz de Durana 2008, 201-204. 
de ser inmediata. Otros aspectos de la curación eran superfluos para una carta anual que solo proporcionaba breves descripciones del evento en cuestión. No se nos informa del nombre del hombre, ni de su enfermedad, la duración de la misma, la fecha o de los medios por los cuales podría haber llegado a conocer las maravillas de Loyola. Fernández solo incluyó los elementos de esta contribución que eran más importantes para la red de información jesuita. Loyola sanó a un individuo vasco cuya condición era desesperada, aunque rápidamente cambió gracias a la intervención santa. En el fondo de estos procedimientos podemos ver la habilidad de los jesuitas para aprovechar, organizar y difundir información a través de su red transoceánica, un ejemplo de lo cual era el repertorio de milagros de Loyola que había preparado Ribadeneyra.

\section{CONCLUSIONES}

Al observar las muchas biografías, relaciones, y cartas que circularon sobre los milagros de Ignacio de Loyola, podemos discernir cómo se recopiló y distribuyó la información en la Monarquía Hispánica durante la edad moderna. Aunque originalmente diseñada para informar a Roma sobre lo que ocurría en las provincias jesuitas, la red de información jesuita permitió la circulación de noticias de intercesiones extraordinarias y de noticias más mundanas, como datos demográficos y actualizaciones sobre las misiones, a nivel intercontinental. Aunque los milagros de Loyola realizados en el Nuevo Mundo no se incluyeron en los decretos de canonización, fueron considerados de interés periodístico y fueron por ello objeto de promulgación. Los miembros de la Compañía hicieron circular las noticias de estos milagros a través de un nexo transatlántico con nodos en España y en los Virreinatos de Nueva España y del Perú. Esta red también involucró a no jesuitas, como Areyzaga en Pamplona.

La colección de milagros de Loyola, que se constituyó como tal a partir de la lista confeccionada por Ribadeneyra antes de la beatificación de 1609, tuvo tanto una proyección local como una proyección global en la monarquía española. Esta colección de milagros se estableció gracias al fácil acceso a la información que existía entre los jesuitas de la edad moderna. Aunque Areyzaga nunca llegaría a experimentar un milagro loyoliano, el vasco continuó extendiendo la reputación de santidad de Loyola mediante un nexo transatlántico. Pese a que en un primer momento había sido importante incorporar las intervenciones sobrenaturales de Loyola en el Nuevo Mundo, esto pronto dejó de ser necesario. Tras la canonización de Loyola, algunos miembros de la Compañía siguieron preparando nuevas listas de milagros de su fundador. En Granada, Andrés Lucas de Arcoñes (1592-1658) escribió una nueva vida de Ignacio con más milagros, mientras que Juan Eusebio Nieremberg (1598-1658) hizo lo mismo en Madrid.

Francisco García (1641-1685), por su parte, escribió otra vida de Ignacio. Finalizada poco antes de su muerte, la Vida, virtudes, y milagros de S[an] Ignacio de Loyola de García se componía de seis libros, de los cuales el último agrupaba los milagros y los organizaba en distintos tipos. Para completar su lista, García hizo uso tanto de las historias que precedieron a la suya, como por ejemplo la de Ribadeneyra, como de los documentos de la canonización y el repertorio de milagros que se hallaban depositados en el Colegio Imperial de Madrid. ${ }^{70}$ García no usó las cartas de los jesuitas procedentes del Nuevo Mundo. Y, sin embargo, la narración de García incluía fábulas americanas como la curación de Fray Álvaro en Lima o el apaciguamiento de los huracanes en el Caribe. ${ }^{71}$

García también añadió una serie de nuevos milagros. Uno de estos narraba como el santo se le había aparecido a Antonio Ruiz de Montoya (1585-1652) en tres ocasiones. A Ruiz de Montoya, también Ilamado "Apóstol del Guaraní», se le conoce por ser el autor de Conquista espiritual, un relato que, publicado en 1639 , narraba la misión jesuita en Paraguay, Uruguay y el sur de Brasil. Según García, en una de sus apariciones Loyola tocó una copia de sus Constituciones. Acto seguido, Ruiz de Montoya sujetó el libro, y fue curado. ${ }^{72}$ La creencia en los poderes intercesores de Loyola llegó también al pueblo mejicano de Guadiana, nombre antiguo de Durango, donde realizó numerosas curaciones, y se extendió a la ciudad de México, en donde su firma tuvo efectos milagrosos similares. ${ }^{73}$ Aunque son solo una pequeña muestra de los muchos milagros narrados por García en la Vida de Ignacio, estos ejemplos, son indicativos de la importancia que tuvieron los milagros americanos en la reputación de la santidad de Loyola. García, sin embargo, no había dependido de las cartas del Nuevo Mundo a la manera de Ribadeneyra, otros jesuitas, o Areyzaga.

\section{FUENTES}

Cabredo, Rodrigo. 1609. Copia de una carta del Padre Rodrigo de Cabredo de la Compañía de Jesus, para el padre Alonso Messia Procurador general por la Provincia del Peru. Barcelona: Sebastián Mathevad y Lorenzo Déu.

Correspondance de Christophe Plantin. 1883-1918. 9 vols. Amberes: J.E. Buschmann.

Covarrubias y Sebastián Orozco. 1611. Tesoro de la lengua castellana, o española. Madrid: Luis Sánchez.

García, Francisco. 1685. Vida, virtudes y milagros de S. Ignacio de Loyola. Madrid: Juan García Infanzón.

Henao, Gabriel. 1689-1691. Averigvaciones de las antiguedades de Cantabria enderezadas principalmente a descubrir las de Gupuzcoa. 2 vols. Salamanca: E.A. García.

Litterae annuae Societatis lesu 1607. 1618. Maguncia: Johann Albini.

Ribadeneyra, Pedro. 1572. Vita Ignatii Loyolae. Nápoles: Giuseppe Cacchio.

Ribadeneyra, Pedro. 1599-1601. Flos sanctorum, o las vidas de los santos. Madrid: Luis Sánchez.

Ribadeneyra, Pedro. 1610. Vida y milagros de Glorioso Patriarca Ignacio de Loyola. Pamplona, Carlos de Labayen.

Ribadeneyra, Pedro. 1920-1923. Confessiones, epistolae aliaque scripta inedita. 2 vols. Madrid: La Editorial Ibérica.

Rocca, Angelo. 1601. De canonizatione sanctorum commentarius. Roma: Guillelmo Facciotti.

Roxas y Contreras, Joseh. 1768. Historia del Colegio Viejo de S[an] Bartholomé...de Salamanca. Segunda parte. 3 vols. Madrid: Andrés Ortega.

Scripta de Sancto Ignatio de Loyola. 1904-1918. 2 vols. Madrid: Gabriel López del Horno.

Tomás de Kempis. 1619. Contemptus mundo. Pamplona: Carlos de Labayen.
70 García 1685, [xxiii].
71 García 1685, 605-606, 634.
72 García 1685, 584.
73 García 1685, 594-596, 599, 617-618. 


\section{BiBLIOgRAFÍA}

Alvar Ezquerra, Manuel. 1997. Vocabulario de indigenismos en las Crónicas de Indias. Madrid: Consejo Superior de Investigaciones Científicas.

Bilinkoff, Jodi. 1999. "The Many 'Lives' of Pedro de Ribadeneyra». Renaissance Quarterly 52 (1): 180-196.

Bouza Álvarez, Fernando Jesús. 2000. Comunicación, conocimiento y memoria en la España de los siglos XVI y XVII. Salamanca: Seminario de Estudios Medievales y Renacentistas.

Bouvier, Claire. 2017. «Le père Pedro de Ribadeneyra (1526-1611), plagiaire du père Dionisio Vázquez (1527-1589)? Le cas de la Vida del Padre Francisco de Borja (1592) de Pedro de Ribadeneyra: écriture, réécriture et émergence d'une figure d'auteur dans la Compagnie de Jésus». En Machines à voler les mots: idéologies, pratiques et techniques du plagiat, ed. Paloma Bravo, Sylvie Laigneau-Fontaine y Giuseppe Sangirardi, 171-187. Dijón: Éditions universitaires de Dijon.

Chaunu, Huguette y Pierre Chaunu. 1955-1959. Seville et l'Atlantique. 12 vols. París: Colin.

Clossey, Luke. 2008. Salvation and Globalization in the Early Jesuit Missions. Cambridge, Reino Unido: Cambridge University Press.

Daston, Lorraine. 1991. «Marvelous Facts and Miraculous Evidence in Early Modern Europe». Critical Inquiry 18(1): 93-124.

Díez de Salazar, Luis Miguel y María Rosa Ayerbe Iríar. 1990-2008. Juntas y diputaciones de Gipuzkoa: Documentos. 31 vols. San Sebastián: Diputación Foral de Guipúzcoa.

Ditchfield, Simon. 1995. Liturgy, Sanctity, and History in Tridentine Italy: Pietro Maria Campi and the Preservation of the Particular. Cambridge, Reino Unido: Cambridge University Press.

Ditchfield, Simon. 1998. «In Search of Local Knowledge: Rewriting Early Modern Italian Religious History». Cristianesimo nella storia 19: 255-296.

Egaña, Antonio de y Enrique Fernández García. 1954-1986. Monumenta Peruana. 8 vols. Roma: Institutum Historicum Societatis lesu.

Fernández de Casadevante Romaní, María Dolores. 2012. «Introducción a la historia de la imprenta en Guipúzcoa (1585-1850)». Revista General de Información y Documentación 22: 67-92.

Fernández Zapico, Dionysius y Cándido Dalmases. 1943-1965. Fontes narrativi de S[ancto] Ignatio de Loyola et de Societatis lesu. 4 vols. Roma: Institutum Historicum Societatis lesu.

Friedrich, Markus. 2008. "Circulating and Compiling the Litterae annuae. Toward a History of the Jesuit System of Communication". Archivum Historicum Societatis lesu 77: 3-39.

Friedrich, Markus. 2009. «Government and Information-Management in Early Modern Europe. The Case of the Society of Jesus (15401773)». Journal of Early Modern History 12: 1-25.

García de Castro Valdés, José. 2012. Polanco: el humanismo de los Jesuitas (1517-1576). Bilbao: Mensajero.

Gotor, Miguel. 2002. I beati del papa: santità, inquisizione e obbedienza in età moderna. Florencia: Olschki.

Greenwood, Jonathan E. 2018a. «Readable Flowers: Global Circulation and Translation of Collected Saints' Lives». Journal of Global History 13: 22-45. https://doi.org/10.1017/S1740022817000274

Greenwood, Jonathan E. 2018b. «Floral Arrangements: Compilations of Saints' Lives in Early Modern Europe». Journal of Early Modern History 22 (3): 181-203. https://doi. org/10.1163/15700658-12342577

Greenwood, Jonathan E. 2019. «Tracing the Cult of Ignatius Loyola through Print». Archivum Historicum Societatis lesu 88 (175): 135-181.

Guillausseau, Axelle. 2007. "Los relatos de milagros de Ignacio de Loyola: un ejemplo de la renovación de las prácticas hagiográficas a finales del siglo XVI y principios del siglo XVII». Criticón 99: 5-56.
Medina, Francisca de Borja. 2004. "San Ignacio de Loyola en la fundación de la provincial del Nuevo Reino y Quito: la tempestad calmada». Theologica Xaveriana 152: 607-628.

Millas, José Carlos. 1968. Hurricanes of the Caribbean and Adjacent Regions, 1492-1800. Miami: Academy of the Arts and Sciences of the Americas.

Mujica Pintilla, Ramón. 2013. Rosa limensis: Mística, política e iconografía en torno a la patrona de América. México: Centro de estudios mexicanos y centroamericanos.

Nelles, Paul. 2010. "Seeing and Writing: The Art of Observation in the Early Jesuit Missions». Intellectual History Review 20 (3): 317-333.

Nelles, Paul. 2014. «Chancillería en colegio: la producción y circulación de papeles jesuitas en el siglo XVI». Cuadernos de Historia Moderna Anejo XIII: 49-70.

Nelles, Paul. 2015. "Cosas y cartas: Scribal Production and Material Pathways in Jesuit Global Communication (1547-1573)». Journal of Jesuit Studies 2 (3): 421-450.

O'Malley, John W. 2013. Saints and Devils Incarnate: Studies in Jesuit History. Boston: Brill.

Otazu, Alfonso y José Ramón Díaz de Durana. 2008. El espíritu emprendedor de los vascos. Madrid: Silex.

Pacheco, Juan Manuel. 1959-1986. Los jesuitas en Colombia. 3 vols. Bogotá: Pontificia Universidad Javeriana.

Padberg, John W., Martin D. O’Keefe y John L. McCarthy. 1994. For Matters of Greater Moment: The First Thirty Jesuits General Congregations. San Luis, Misuri, Estados Unidos: Institute of Jesuit Sources.

Palomo, Federico. 2005. «Corregir letras para unir espíritus. Los jesuitas y las cartas edificantes en el Portugal del siglo XVI». Cuadernos de Historia Moderna Anejo IV: 57-81.

Papa, Giovanni. 2001. Le cause di canonizzazione nel primo periodo della Congregazione dei Riti (1588-1634). Roma: Urbaniana University Press.

Pérez Mallaína, Pablo. 1998. Spain's Men of the Sea: Daily Life on the Indies Fleets in the Sixteenth Century. Trad. Carla Rahn Phillips. Baltimore, Maryland, Estados Unidos: Johns Hopkins University Press.

Reading, Alison J. 1990. "Caribbean Tropical Storm Activity over the Past Four Centuries». International Journal of Climatology 10: 365-376.

Roldán Figueroa, Rady. 2016. "Pedro de Ribadeneyra's Vida del P. Ignacio de Loyola (1583) and Literary Culture in Early Modern Spain». En Exploring Jesuit Distinctiveness: Interdisciplinary Perspectives on Ways of Proceeding within the Society of Jesus, ed. Robert A. Maryks, 156-174. Leiden: Brill.

Ruiz Astiz, Javier. 2014. "Más útil para la enseñanza de los niños: dos impresores antes los tribunales reales de Navarra (1607-1608)». Anales de Documentación 17 (1): 1-14.

Schwartz, Stuart B. 2015. Sea of Storms: A History of Hurricanes in the Greater Caribbean from Columbus to Katrina. Princeton, Nueva Jersey, Estados Unidos: Princeton University Press.

Voet, Leon. 1969-1972. The Golden Compasses. The History of the House of Plantin-Moretus. 2 vols. Ámsterdam y Londres: Vangendt y Routledge.

Weckmann, Luis. (1962) 1992. The Medieval Heritage of Mexico. Trad. Frances M. López Morillas. Nueva York: Fordham University Press.

Wilkinson, Alexander S. y Alejandra Ulla Lorenzo. 2016. Iberian Books Volumes I/ \& III. Leiden: Brill.

Wright, Anthony David. 2010. "La sua santità non inclina niente: The Papacy and the Canonization of Ignatius Loyola». En Ite inflammate omnia. Selected Historical Papers from Conferences Held at Loyola and Rome in 2006, ed. Thomas M. McCoog, 441-455. Roma: Institutum Historicum Societatis lesu.

Zambrano, Francisco. 1961-1977. Diccionario Bio-Bibliográfico de la Compañía de Jesús en México. 16 vols. México: Editorial Jus.

Zubillaga, Félix y Miguel Ángel Rodríguez. 1956-1991. Monumenta Mexicana. 8 vols. Roma: Institutum Historicum Societatis lesu. 